Proc. Indian Acad. Sci. (Earth Planet. Sci.), Vol. 90, No. 3, November 1981, pp. 211-215.

(c) Printed in India

\title{
Seepage loss from a canal in Sri Lanka measured using tritium tracer
}

\author{
J K DHARMASIRI, K G DHARMAWARDENA, \\ P MANCHANAYAKE*, M M G NAVARATNA*, \\ D A WICKREMARACHCHI** and P S GOEL $\dagger$ \\ Radioisotope Centre, University of Colombo, Sri Lanka \\ *Deparment of Irrigation, Colombo, Sri Lanka \\ **Atomic Energy Authority of Sri Lanka, Colombo, Sri Lanka \\ †Department of Chemistry, Indian Institute of Technology, Kanpor 208 016, India
}

MS received 24 April 1981

\begin{abstract}
Using single borehole dilution technique, and tritiated water as tracer, lateral flow rate of water near the phreatic line has been measured at 24 points along the banks of an unlined canal. Permeability values tange from $0.5 \times 10^{-6} \mathrm{~m} \mathrm{sec}-1$ to $34 \times 10^{-6} \mathrm{~m} \mathrm{sec}^{-1}$; the median value being $5 \times 10^{-6} \mathrm{~m} \mathrm{sec}-1$. The seepage loss is estimated to be $5 \times 10^{-5} \mathrm{~m}^{3} \mathrm{sec}^{-1} \mathrm{~m}^{-1}$. For the entire canal the value is 0.74 $\mathrm{m}^{3} \mathrm{sec}^{-1}$ which is $12 \%$ of the total flow. Limitations and merits of the technique are discussed.
\end{abstract}

Keywords. Canal seepage; tritium tracer; seepage loss; borehole dilution; nuclear hydrology.

\section{Introduction}

Usefulness of radioactive tracers to measure seepage loss from canals has been clearly demonstrated (Kaufman and Todd 1962; Krishnamurthy and Rao 1969). However, the applications have not been extensive enough, and the technique still seems to remain in the hands of nuclear experts rather than the field engineers. In this paper we present results on extensive measurements of seepage velocity along an unlined canal using tritium tracer. These results demonstrate not only that the method is simple enough to be adopted by persons not necessarily experts in nuclear techniques, but also that it gives reasonable values of in-situ feld permeability and seepage loss.

\section{Geohydrological considerations}

Experiments were carried out on a canal in Sri Lanka which was commissioned in 1966. A reservoir impounds the water of river Kala Oya by means of a barrage

to whom all correspondence should be addressed. 
on the river course. From the resorvoir, water is taken for irrigation down slope by means of two canals each on either side of the river. Seepage experiments were done on the canal flowing to the right side of the river ( $R$ B Canal). The canal passes through the soil overburden which primatily consists of sandy clay mixed with pebbles. Marked variation in soil texture is seen. The overburden, which lies on fractured basement rocks, is about $4 \mathrm{~m}$ thick. At several positions, ponds of water have been formed along the banks of the canal in regions where the canal crosses old tanks. (A tank is a formation to hold rain water, and is constructed by raising an earth embarkment on a sloping terrain at the lower perimeter of the catchment area).

\section{Experimental}

A typical cross section of the canal is shown in figure 1. A convenient segment of the canal, about $4 \mathrm{~km}$ long, was selected. Holes were drilled on both the banks by a $10 \mathrm{~cm}$ diameter hand auger. These went below the phreatic line generating a water column of about half a metre $(10 \mathrm{~cm}$ to $110 \mathrm{~cm})$. The holes were kept uncased. Occasionally large pebbles blocked the passage of the auger and forced the abandonment of such holes. Tritiated water $(10 \mathrm{ml} ; 1$ micro-curie) was introduced into each hole by means of a transfer tube. The tracer was well mixed by gently blowing air bubbles through the water column. A $10 \mathrm{ml}$ capacity lead bucket was used to collect samples of water at 6 hourly intervals during the day time and $10 \mathrm{hr}$ intervals during nights for four days.

In the laboratory, $1 \mathrm{ml}$ fraction of a decanted sample was mixed with INSTA-GEL and its activity was counted with a Tri-Carb (Model 3300, Packard) liquid scintillation counter. In most cases an exponential decrease of activity in the hole was clearly seen. Some sites gave erratic results and had to be discarded during data processing.

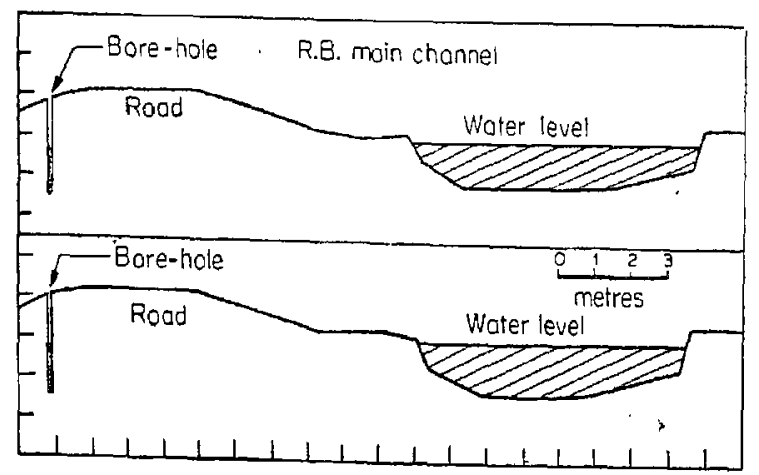

Figure 1. Cross section of the canal at two typical bore-hole positions. Each division on the graph is one metre. 


\section{Results and Discussion}

The rate of flow of water, $Q$ is calculated from the following relation (Halevy et al 1967)

$$
Q=\frac{U}{t} \ln \frac{c_{0}}{c}
$$

Where $U=$ dilution volume of the borehole, and

$$
t=\text { time during which the initial activity } c_{0} \text { becomes } c \text {. }
$$

Since this water flows through a cross sectional area $h d$ where $h$ is the height of the water column in the borehole whose diameter is $d$, we can calculate the linear flow velocity $v$ from $Q$ using the relation:

$$
v=\frac{Q}{h d}=\frac{U}{t} \ln \frac{c_{0}}{c} \cdot \frac{1}{h d}=d\left[\frac{\pi}{4} \cdot \frac{1}{t} \cdot \ln \frac{c_{0}}{c}\right]
$$

It is only the diameter of the borehole that enters into the final expression. If the hydraulic gradient at a borehole is ' $g$ ' the velocity of seepage is related to permcability $k$ by $(v=k g)$.

Equation (1) gives only an apparent velocity which has to be corrected for diffusional dilution and for geometry effects, the latter arising due to the flow in a borehole being larger than in the undisturbed soil. The corrected velocity $v_{c}=$ $\left(v-v_{d}\right) / 2$ where $v_{d}$ is velocity due to dilution by diffusion effects and the factor of 2 in the denominator is a correction for the geometry factor (Halevy et al 1967). Assuming a constant value for the diffusivity $\left(D=2 \times 10^{-5} \mathrm{~cm}^{2} \mathrm{sec}^{-1}\right)$ of water in soil (Goel et al 1977; Dharmasiri et al 1982) $v_{d}$ is calculated as $\sim 10^{-5} \mathrm{~cm} \mathrm{sec}^{-1}$. In clayey soils $v_{d}$ may be smaller, and since the value of $v$ is already low for such soils, the correction is very large. In figure 2 we show two histograms for $k$, one with corrections for diffusional effects and the other without corrections. When an average value of $k$ is taken only a marginal correction is needed for diffusion effects, which has been made.

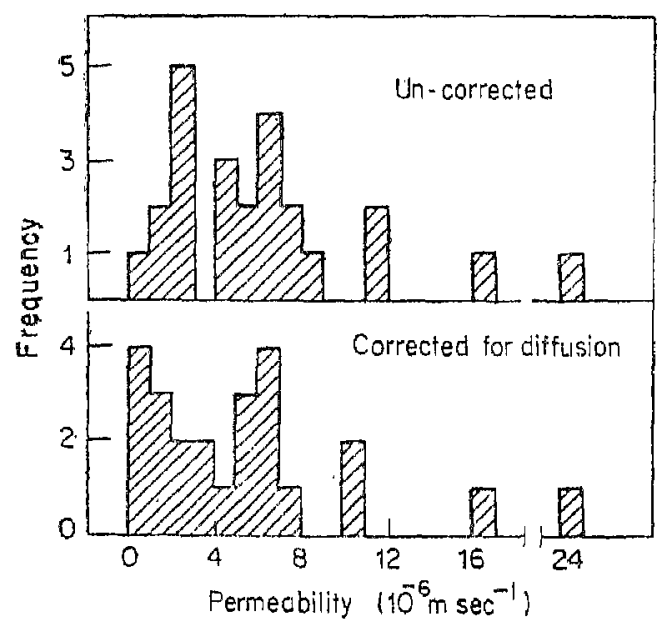

Figure 2. Histogram showing permeability values for different bore-holes. The lower graph is obtained after making a correction for dilution due to diffusion. Note that the correction is significant only for low permenbilities. 
The values of permenbility obtained are well within the ranges measured for loams and silts (Halevy et al 1967). Average value of $k$, after making all the corrections, is $6 \times 10^{-6} \mathrm{~m} \mathrm{sec}^{-1}$. The median value would be more like $5 \times$ $10^{-6} \mathrm{~m} \mathrm{sec}^{-1}$, though one would need larger sets of data to ascertain whether the two values are really different. For the present purpose $5 \times 10^{-6} \mathrm{~m} \mathrm{sec}^{-1}$ is taken as a representative value for $k$.

Some bias is introduced in rejection of those sets of data where the activity did not decrease exponentially. Possible reasons for such a behaviour are the presence of layered flow through a borchole or a change in the size of the borehole during a run due to lateral collapse of its walls. Clearly such boreholes would correspond to more permeable (sandy) soils and their rejection tantamounts to pushing the average to the lower side.

\section{Seepage loss}

The seepage loss for the canal depends on its dimensions, the permeability of the soil, distance of the governing drainage and the head difference. The tracer method gives us a reasonably good value of in situ, $k$ the permeability. Except when steady condition can be obtained, the discharge, as calculated from a theoretical formula might only give an approximate value.

For a canal of trapezoidal cross-section flowing in a permeable medium of infinite depth with deep water table, the amount of water seeping out per unit length is given by Vedernikov (1934) as :

$$
q=k(B+A H) \text {. }
$$

Here, $q=$ seepage loss per unit time per unit length, $B=$ width of the canal at the water level, $H=$ height of water in the canal, and $A$ is a function depending on $B / H$ and $\cot \alpha$ where $\alpha$ is the inclination of the bank with the horizon. Witlin ranges of $B, H$, and $\alpha$ that are admissible for the present case, the value of $A$ would vary from 2.8 to 3.2 (Harr 1962). We can take an average value of 3 . The value of $g / k$ comes out to be $11 \mathrm{~m}$.

On the other hand if we assume that the basement fractured rock (below about $4 \mathrm{~m}$ ) is impermeable, we have to use a different expression for the calculation of $q / k$. The solution is given by Muskat (1937) and Vedernikov (1934) and is available in graphical form in standard books (Harr 1962). We now have

$$
q / k=\cot \alpha H \cdot f .(B / H, T / H)
$$

For admissible values of $B / H, T / H$, and $\alpha,(T=4 \mathrm{~m})$ the value of $q / k$ is 9 to $10 \mathrm{~m}$. It may however, be pointed out that a basement of fractured rocks, as these are in the present case, may not be completely impermeable. Still a reasonable value for $q \mid k$ is obtained.

Another limiting case that may be considered is the influence of the horizontal drainage layer. Pavlovsky solved this problem in 1936 (Aravin and Numerov 1953). The seepage loss is

$$
q / k=(B+2 H)=10 \mathrm{~m}
$$


All the three limiting cases give a value of about $10 \mathrm{~m}$ for $q / k$. Unfortunately we did not measure phreatic lines for the boreholes. This would have probably given us some further clues for using a more appropriate expression for $q / k$. The seepage loss per unit length is

$$
q=10 k=5 \times 10^{-5} \mathrm{~m}^{3}(\mathrm{~m} \mathrm{sec})^{-1}
$$

The length of the canal is $14.76 \mathrm{~km}$ and the flow discharge is 210 cusecs. The seepage Ioss for the entire canal is calculated as $0.74 \mathrm{~m}^{3} \mathrm{sec}^{-1}$ (26 cusecs) which is about $12 \%$ of the inflow. The value is not too unreasonable for a fresh canal flowing through sandy clay mixed with pebbles. Accuracy could be improved by measuring the canal parameters and $k$ throughout the reach of the canal and also by recording the phreatic lines at the borehole sites.

\section{Acknowledgenents}

The atuthors express their sincere gratitude to Professor P P GL Siriwardene, Atomic Energy Authority of Sri Lanka, for encouraging nuclear hydrological work in Sri Lanka. They have benefited by discussions with Dr W Drost (IAEA). P S Goel is indebted to International Atomic Energy Agency, Vienna, for support that enabled him to particjpate in this work. The authors thank Mr S?s Amarasekera for maintenance of equipment and other help and appreciate the cooperation of United Nations Development Programme at Colombo.

\section{References}

Aravin V I and Numerov S N 1953 Theory of flow in undeformable porus media (Isreal Program for Scicntific Translations Lid, translated in 1965) pp 189

Dharmasiri J K, Dharmawardena K G, Wijesinghe M W P, Thiranagama P, de Mel ID T, Wick* remarachchi: D A and Goel P S 1982 Nordic Hydrology, (in press)

Goel P S, Datta P S and Tanwar B S 1977 Nordic Hydrology 8211

Halewy E, Moser H, Zellhofer O and Zuber A 1967 In : Isotopes in Hydrology (IAEA, Vienna) pp 531

Harr M E 1962 Groundwater and seepage (New York: Mc Graw Hill) pp 231

Kaufman W J and Todd D K 1962 In : Tritiun in the physical and biological sciences, Vol. 1 (IAEA, Vienua) pp 83

Krishnamurthy K and Rao S M 1969 J. Hydrol. 9277

Muskat M 1937 The flow of homogeneous fluids through portls medin (New York: McGraw-Hill) (reprinted by J.E. Edwards publisher Inc. Ann Arbor, 1946)

Vedernikov V V 1934 Seepages from channels (Gosstroiizdat, quoted in Harr, 1962; and in Aravin and Numerov, 1953). 